\title{
A ATUAÇÃO DO TERCEIRO SETOR COMO GRUPO DE PRESSÃO
}

\author{
Vivian de Almeida Gregori Torres ${ }^{1}$
}

RESUMO: O estudo tem por foco a atuação do terceiro setor como grupo de pressão e a consequência desta ação, enquanto meio de correção do mal funcionamento do Estado e atenuação da crise da representatividade. Neste sentido, a análise sinaliza a passagem da democracia representativa para a participativa, tendo a sociedade civil organizada, utilizada como instrumento. Para tanto, num primeiro momento será estudada a função da sociedade civil organizada, em seguida será analisada a influência do terceiro setor no Estado e, por final, a atuação deste como grupo de pressão, a partir, primordialmente da revisão de literatura sobre o assunto.

PALAVRAS-CHAVE: Democracia, Representação, Cidadania, Terceiro Setor, Grupo de Pressão.

\section{THE ACTION OF THE THIRD SECTOR AS A PRESSURE GROUP}

\begin{abstract}
The study focuses on the performance of the third sector as a pressure group and the consequence of this action, as a means of correcting the malfunctioning of the State and attenuation of the representativeness crisis. In this sense, the analysis signals the transition from representative to participatory democracy, with organized civil society being used as an instrument. To do so, the function of organized civil society will be studied first, then the influence of the third sector in the State and, finally, the influence of the third sector as a pressure group will be analyzed, starting from the literature review on the subject.
\end{abstract}

KEY WORDS: Democracy, Representation, Citizenship, Third Sector, Pressure Groupe.

\footnotetext{
${ }^{1}$ Doutora em Direito do Estado pela Faculdade de Direito da Universidade de São Paulo. Mestre em Direito Político e Econômico pela Universidade Presbiteriana Mackenzie. Especialista em Direito Empresarial pela Universidade Presbiteriana Mackenzie. Graduada pela Faculdade de Direito de São Bernardo do Campo. Professora na Universidade Nove de Julho. Presidente da Comissão de Pesquisa e Pós-Graduação em Direito da OAB/SP. Relatora da $2^{\text {a }}$ Câmara do Tribunal de Ética e Disciplina da OAB/SP. Conselheira da OAB/SP. gregori@gregorihabe.com.br
} 


\section{INTRODUÇÃO}

O mundo moderno adotou a democracia representativa, na qual o povo elege os representantes que, ao final, serão a "personificação" do Estado. O voto é a forma do cidadão influenciar/participar do poder. Por meio de seus representantes eleitos, a sociedade sinaliza as políticas desejadas e responsabiliza os governantes pelas ações praticadas e pelos resultados obtidos e/ou percebidos.

Contudo, o depósito do voto nas urnas, não tem sido capaz de orientar e influir o locus governamental, que tem caminhado em muitos momentos a contrário sensu do desejado pela sociedade.

Diante deste cenário, o cidadão passou a buscar uma forma mais contundente de atuação, encaminhando-se para a democracia participativa, como forma de correção do mal funcionamento estatal.

Na busca de meios para agir, a sociedade, reconheceu o terceiro setor como um instrumento capaz de atuar como grupo de pressão, de tal forma a influir no Estado e, por consequência, nas políticas públicas adotadas. É a moderna participação política do cidadão.

No âmbito da sociedade civil organizada é que se encontra o melhor ambiente para o desenvolvimento da democracia participativa, tendo em vista seu pluralismo, que exerce papel importante no contrapeso do poder do Estado, opondo-se à força da organização estatal, servindo para resguardar a liberdade individual contra a eventual prepotência dos governantes. Aliado a isto, os movimentos, organizações e associações, servem como “captadoras” dos problemas sociais e posteriores transmissoras de tais questões à esfera pública política, institucionalizando os discursos capazes de solucionar os problemas, transformando-os em questões de interesse geral no quadro das esferas públicas.

Esta forma do terceiro setor influenciar no Estado, é materializada quando este protagoniza o papel de grupo de pressão, sendo que tal atuação encontra espaço em razão da crise da representatividade que padece a sociedade. O cidadão acaba associando-se com outros que partilhem dos mesmos interesses, com o claro intuito de influir no processo decisório, vez que a atuação tradicional por meio dos políticos e partidos não tem sido muito eficiente.

As entidades civis reúnem todas as características de um grupo de pressão: são grupos organizados, promovem a defesa de interesses e exercem pressão no locus governamental, assim como preparam seus associados de forma a unificar a ação tática e os meios para apresentarem-se ante o Estado com força suficiente para dar sustentação a suas atitudes.

O terceiro setor, enquanto grupo de pressão, têm atividade política e não fins políticos, 
quer influenciar no governo e não exercê-lo. A atuação essencial é sobre a opinião pública e a ação governamental, e, neste aspecto, tem sido muito eficiente, podendo-se constatar a interferência da sociedade civil organizada na esfera dos três poderes, na medida em que faculta a iniciativa popular, depõem Presidente da República e sugestionam a interpretação legislativa.

Feitas estas considerações, o presente trabalho pretende analisar o terceiro setor como instrumento da democracia participativa na medida em que atua como grupo de pressão.

Assim, num primeiro momento será estudada a função da sociedade civil organizada, em seguida será analisada a influência do terceiro setor no Estado e, por final, a atuação deste como grupo de pressão, a partir, primordialmente da revisão de literatura sobre o assunto.

Deste modo, pretende-se demonstrar que interferência direta do terceiro setor na vontade estatal, funciona como uma verdadeira ferramenta capaz de reorientar os resultados, no sentido de forçar o acatamento da vontade popular, constituindo-se em verdadeira forma de exercício da democracia participativa.

\section{Função da sociedade civil organizada.}

A sociedade civil, considerada enquanto número, contingente de pessoas, a princípio, poderia ser pensada como arma política. Contudo, assevera Maurice Duverger que "só é uma arma política verdadeira quando as massas são organizadas (...) o número é inseparável da organização” (DUVERGER, 1968, p. 256). A grande massa da população era excluída do círculo estreito em que se desenvolvia a luta pelo poder, passando a constituir força política com a elevação geral do nível de vida e de cultura, a partir da Revolução Industrial. Esse foi o momento em que passou a tomar consciência de sua miserabilidade e das possibilidades de sair dela, encontrando meios de agir², que perpassam do sufrágio às organizações políticas, representadas principalmente pelos partidos e grupos de pressão. (DUVERGER, 1968, p. 256/258).

O elo entre a sociedade civil e a democracia já havia sido analisado nos primeiros escritos liberais, como o de Alexis de Tocqueville, que valoriza em sua obra o direito associativo, ao mencionar que "depois da liberdade de agir sozinho, a mais natural ao homem é a de combinar os seus esforços com os esforços de seus semelhantes e agir em comum. Por isso, o direito de associação parece-me quase tão inalienável, pela sua natureza, quanto a

\footnotetext{
2“A regulamentação de processos de organização social, que permite enquadrar imensas massas humanas, educálas politicamente, mobilizar-lhes as energias, canalizar e orientar sua ação, criou instrumentos de ação política de grande eficácia”. (DUVERGER, 1968, p. 258).
} 
liberdade individual”. (TOCQUEVILLE, 1987, p. 149).

Nesse contexto, ressalta-se que a sociedade civil, quando organizada em grupos de interesses, tem por função na democracia ampliar o pluralismo político e intervir no governo ${ }^{3}$. Também influi na relação que se estabelece entre os detentores do poder e a conjuntura social onde é exercido e, a depender do regime e do quanto está organizada, poderá intervir mais ou menos na busca do eterno paradoxo liberdade individual/bem-estar social. (CAGGIANO, 1995, p. 25/26).

Na democracia é que a sociedade civil organizada se manifestará em sua plenitude, tendo um papel importante na forma como o cidadão de fato alcançará a participação no exercício do poder, encontrando meios para intervir nas decisões governamentais. É a forma do povo conduzir o governo e não o contrário.

Evelina Dagnino compartilha da mesma ideia, acrescentando que a Constituição de 1988 consagrou o princípio da participação para além do simples direito ao voto, no qual a participação da sociedade civil busca relações mais diretas com o Estado, muito embora essas relações, no sentido de uma atuação conjunta do Estado e da sociedade civil, sejam carregadas de tensão. Essas relações têm graus de variação a depender do quanto compartilham as partes envolvidas do mesmo projeto político, constituindo a efetiva partilha do poder o ponto central dessa tensão, uma vez que os Executivos resistem a partilhar o seu poder exclusivo de decidir as políticas públicas, atribuindo à sociedade civil apenas o caráter consultivo. (DAGNINO, 2002).

Por outro lado, a sociedade civil quer participação efetiva quanto às decisões de políticas públicas, bem como promover o controle social sobre essas. Muito embora essa relação seja permeada de conflitos, a sociedade civil e o Estado têm alcançado grau razoável de sucesso e estabilidade quando atuam de forma complementar e/ou instrumental um do outro. Tem-se, ainda, que a ampliação da participação da sociedade civil vem a implementar o ajuste neoliberal, que exige o encolhimento das responsabilidades sociais do Estado, de forma a contemplar a extensão da cidadania e o aprofundamento da democracia, bem como a presença mínima do Estado, isentando-o de forma progressiva de seu papel garantidor de direitos. (DAGNINO, 2002, p. 141/153)

A sociedade civil, ante seu pluralismo, exerce papel importante no contrapeso do poder

\footnotetext{
${ }^{3}$ É que, remarca Karl Loewenstein "a essência da democracia constitucional consiste em que os mais diversificados grupos pluralistas possam participar, ilimitadamente, do processo econômico e político”. (Apud. CAGGIANO, 1995, p. 87)
} 
do Estado, opondo-se à força da organização estatal, servindo para resguardar a liberdade individual contra a eventual prepotência dos governantes. (FERREIRA FILHO, 1979, p. 87). Sendo composta por movimentos, organizações e associações, serve como “captadora” dos problemas sociais e posterior transmissora de tais questões à esfera pública política. Além disso, institucionaliza os discursos capazes de solucionar os problemas, transformando-os em questões de interesse geral no quadro das esferas públicas (HABERMAS, 2011, p. 100).

Luis Sanchez Agesta introduz a sociedade civil na política, expondo que a política é uma atividade social que decide a configuração de uma comunidade, desenvolvendo, defendendo ou transformando a ordem vinculante com que se organiza essa comunidade. A política é uma atividade social de decisão, sendo a ação política concebida como o poder supremo de uma comunidade independente, que decide sobre o bem público. (SANCHEZ AGESTA, 1979, p. 66/113).

Karl Loewenstein traz os grupos pluralistas da sociedade civil como controle vertical do poder, visto que influenciam nas decisões políticas, bem como no próprio poder político. É por meio da união dos indivíduos que esses alcançam a possibilidade de oferecer resistência aos detentores do poder estatal, constituindo barreiras e freios frente ao poder político, chegando a modelar o próprio detentor do poder. (LOEWENSTEIN, 1976, p. 422/424).

Para Habermas, a sociedade civil tem viés de força condutora do poder político, “o poder social vale como medida para a força de imposição de interesses organizados” (HABERMAS, 2011, p. 59), usando como meio para tanto as eleições gerais e a concorrência entre os partidos, objetivando a implementação das políticas oriundas da sociedade, de tal sorte a transformá-las em decisões obrigatórias. Segundo seu entendimento, o processo é circular, no qual a sociedade/cliente liga-se aos partidos, que alcançam o poder político e implementam as pretensões dos clientes/sociedade. O movimento circular mantém-se pelo temor que os partidos estabelecidos têm de perder sua legitimação provocada pelas vozes de protesto e pelos que não são eleitores. (HABERMAS, 2011, p. 59/61).

De acordo com o filósofo, a esfera pública política é uma estrutura comunicacional, enraizada no mundo da vida através da sociedade civil. O espaço público político é uma caixa de ressonância “onde os problemas a serem elaborados pelo sistema político encontram eco" (HABERMAS, 2011, p. 92). Em ambiente democrático, a sociedade deve reforçar a pressão, não só percebendo e identificando os problemas, mas tematizando-os, discutindo-os e dramatizando-os de forma eficaz o suficiente para que venham a ser assumidos e elaborados 
pelo complexo parlamentar, promovendo posteriormente o controle do tratamento das questões no âmbito do sistema político.

Habermas descreve a esfera pública como "uma rede adequada para a comunicação de conteúdos, tomadas de posição e opiniões; nela os fluxos comunicacionais são filtrados e sintetizados, a ponto de se condensarem em opiniões públicas enfeixadas em temas específicos”. (HABERMAS, 2011, p. 93).

Já Giovanni Sartori dá destaque para a opinião pública, na medida em que a democracia exige um público que manifesta opiniões. O conceito de opinião pública situa-se no contexto da democracia representativa e a institui em grande escala. Tem-se que a democracia representativa não se caracteriza pelo “governo do saber” e sim pelo “governo da opinião”. A opinião pública o é não somente porque é do público, mas também, porque diz respeito a objetos e matérias que são de natureza pública no sentido de interesse geral, bem comum e essencialmente a coisa pública, ou seja, ela existe quando há difusão entre o público e refere-se à coisa pública. ${ }^{4} \mathrm{~A}$ opinião pública é a fonte da legitimidade e da condução de um bom governo, sendo caracterizada por aquelas opiniões que assumem certa relevância política. (SARTORI, 2012, p. 169/171).

A partir da opinião pública a sociedade civil encontra outra função, a de exercer pressão sobre o Estado de forma que este atenda às necessidades sociais e alcance o bem-comum.

Do quanto analisado, percebe-se que a sociedade civil organizada, ante a defesa da necessidade de espaços públicos que visem a vitalização da vida social, de forma a ampliar os espaços decisórios da democracia política, abriu caminho para uma outra forma de democracia, a participativa. (DURIGUETTO, 2007, p.124). Em resumo, se extrai como funções da sociedade civil: a) coletar os ecos dos problemas sociais que ressoam nas esferas privadas e levá-los para a esfera pública política; b) exercer influência sobre a formação institucionalizada da opinião e da vontade da sociedade; c) constituir espaços públicos destinados a promover o debate no interior da sociedade civil com relação a temas de seu interesse e como espaço de democratização da gestão estatal; d) influenciar e conduzir o poder político; e) resguardar a liberdade ante o Estado opressor; e) operar a democracia por meio da opinião pública emanada do seio da sociedade civil; f) exercer pressão sobre o Estado a fim de que esse cumpra o bemcomum e atenda às necessidades sociais; g) abrir caminho para a democracia participativa.

\footnotetext{
4“(...) la opinión pública puede definirse, en primera instancia, así: un público, o una multiplicidad de públicos, cuyos estados mentales difusos (opiniones) interactúan con los flujos de información sobre el estado de la cosa pública”. (SARTORI, 2012, p. 171).
} 


\section{2. $O$ terceiro setor e seu poder de influenciar no Estado}

Nas democracias tradicionais, a relação entre a sociedade e o governo se consubstancia com a eleição de representantes - ou seja, a forma do cidadão influenciar/participar no Estado é por meio de seus representantes, por intermédio deles a sociedade sinaliza as políticas desejadas e responsabiliza os governantes pelas ações praticadas e pelos resultados obtidos e/ou percebidos.

Contudo, a sociedade moderna clama por mais participação, surgindo, assim, diuturnamente, novas formas participativas que buscam ampliar o espaço democrático da vida política a partir de uma visão crítica do sistema representativo e da procura de uma maior eficiência econômica e social do uso dos recursos públicos. Estas novas faces participativas proporcionam o alargamento da educação política e do exercício da cidadania, além de auxiliar no controle do cumprimento dos compromissos feitos pelos governantes e de identificar e captar a necessidade de novas políticas públicas. ${ }^{5}$

Nesta busca de novas formas participativas, a sociedade identificou o terceiro setor como instrumento ${ }^{6}$ capaz de oportunizá-las, e ele passou a influenciar no Estado por "delegação" da sociedade. ${ }^{7}$ Em certa medida, isto se deu com o advento da reestruturação da administração pública. Após a Segunda Guerra Mundial, o modelo de Estado de bem-estar social foi muito difundido. Este padrão de intervenção sócio-econômica, entretanto, passa a apresentar dificuldades de efetivação devido à recessão econômica enfrentada no final dos anos 1970. Diante desta situação, o Estado busca alternativas para provisionar a produção de bens, serviços sociais e econômicos de forma menos onerosa, surgindo o Estado Regulador que impõe um novo padrão de gestão pública, de perfil neoliberal, que prescindia a diminuição da "máquina administrativa".

Em anos subsequentes, quando a pauta política brasileira passa a abrandar a desestatização e buscar um atendimento mais assistencialista, a partir da ideia de um Estado

\footnotetext{
5“O Princípio democrático impõe a integração do povo no processo político. Idealmente reclama que todos os seus componentes dele participem. Exige, numa palavra, que ao povo seja confiado o máximo de participação possível”. (FERREIRA FILHO, 1979, p.145).

6“Cuando el individuo aislado se une con otros en virtud de una comunidad de interés, tiene entonces la posibilidad de ofrecer mayor resistencia a los detentadores del poder estatal que si tuviese que enfrentarse aisladamente: unido con otros, ejerce una influencia sobre las decisiones políticas que corresponde a la fuerza de su grupo". (LOEWENSTEIN, 1976, p. 423).

7 “A participação das entidades de direito privado sem fins lucrativos mostra-se primordial no auxílio ao Estado para atingir os objetivos constantes da Constituição e seus desdobramentos infraconstitucionais, repartindo entre si a responsabilidade da assistência social e outros direitos sociais, vez que nem sempre é possível exclusivamente ao Estado administrar a questão social e cumprir a função estatal a contento, apesar de sua obrigação neste sentido”. (TEIXEIRA, 2011, p. 35).
} 
social, o mesmo fenômeno de fomento ao terceiro setor é assistido. Contudo, neste caso, motivado pela falta de capacidade do Estado em atender a demanda necessária, o que veio a ampliar ainda mais a influência do terceiro setor na definição e execução de políticas públicas. Tal influência é avultada por incentivo do próprio Estado no momento em que cria diversas modalidades de conselhos gestores de políticas públicas nas mais diversas esferas da organização estatal $^{8}$, promove audiências públicas para debater projetos, especialmente no âmbito do legislativo, cria ouvidorias destinadas a medir reclamações e denúncias dos cidadãos quanto aos serviços públicos, promove o orçamento participativo, dentre outras iniciativas implementadas pelo Estado. Nestas situações, o terceiro setor se faz presente como interlocutor dos vários grupos sociais, exercendo assim sua influência de forma direta no Estado.

Outra forma do terceiro setor influenciar no Estado, como já mencionado, é quando protagoniza o papel de grupo de pressão. ${ }^{9}$ Em razão da crise da representatividade que padece a sociedade, este acaba por "associar-se com outros que lhe partilhem os interesses, a fim de influir no processo decisório" (FERREIRA FILHO, 1979, p. 164), entendendo ser esta forma muito mais eficiente do que a atuação tradicional por meio dos partidos políticos. Tal assertiva é facilmente compreendida partindo-se da definição de grupo de pressão estabelecida por Roger-Gérard Schwartzenberg, para o qual “um grupo de pressão pode definir-se como uma organização constituída para defender interesses, exercendo pressão sobre os poderes públicos a fim de deles obter decisões conformes a esses interesses”. (SCHWARTZENBERG, 1979, p. 614). Dos elementos contidos na definição citada, o terceiro setor reúne os três: é um grupo organizado; promove a defesa de interesses e exerce pressão no locus governamental.

Segundo Andres Serra Rojas o poder de decisão em forma coativa é uma das características do estado moderno (SERRA ROJAS, 1971, p. 713); sob este aspecto a sociedade encontrou nas entidades que compõe o terceiro setor uma forma de organizar-se, quer seja por

\footnotetext{
8“E querendo alguns - outros não - conselhos gestores de políticas públicas exercem o poder popular determinado pela Constituição da República e provocam uma concepção de partilha do poder, de mudança na gestão pública (...) E a forma encontrada pelo legislador constituinte de 1988, para permitir a participação da sociedade civil organizada, de modo direto, foi por meio da participação nos diversos conselhos gestores, voltados às políticas públicas sociais inseridas na Constituição Federal”. (ALVES, 2005, p. 218).

${ }^{9}$ Sob este aspecto, Odete Medauar afirma que o grande número de entidades e associações privadas que floresceram nos últimos anos exercem uma pressão sobre o poder estatal na busca do atendimento dos interesses que defendem. (MEDAUAR, 1999, p. 27).
} 
interesses particulares, ${ }^{10}$ quer seja por interesses públicos, ${ }^{11}$ para compelir o governo a tomar decisões que estejam ao encontro de seus interesses e objetivos. Neste aspecto o terceiro setor tem sido muito atuante, na medida em que se faz presente nas casas legislativas sempre que uma lei de seu interesse esteja na pauta de votação, promovem abaixo assinados, interpõem ações coletivas, organizam passeatas, mobilizam a imprensa, ocupam cargos em conselhos da administração pública, elaboram e coordenam leis de iniciativa popular dentre outras formas de pressionar o Estado de maneira a influenciá-lo, consolidando assim os instrumentos de pressão inseridos em uma democracia mais participativa.

As situações aludidas podem ser consideradas como formas lícitas do terceiro setor promover pressão no locus governamental de tal forma a influenciá-lo. No entanto, chama-se a atenção para os meios menos recomendáveis de fazê-lo, como no caso de prestar apoio financeiro ou ideológico aos partidos políticos ou candidaturas, funcionando como “organizações anexas”, ${ }^{12}$ de acordo com a definição dada por Maurice Duverger, ou como meio de corrupção daqueles que detêm o poder.

Sobre este aspecto, a inquietação do meio acadêmico tende a focar sua preocupação na atuação do terceiro setor, enquanto grupo de pressão, com relação às questões de cunho econômico. Contudo, a economia é uma das partes que compõem o todo e no modelo de sociedade atual possui papel relevante e deve ser acomodada nas relações sociais, não como vilã da história e culpada por todos os males na acepção marxista, mas como algo ainda "instrumental" que deve ser conformado na sociedade deste século. Nesta conformação, identifica-se a atuação do terceiro setor em prol de ambos os lados, bom e ruim, da economia, numa tentativa de equalização das forças.

\section{O terceiro setor como grupo de pressão}

Para melhor aclarar a questão a ser apresentada, entende-se necessário percorrer a opinião de alguns doutrinadores, com relação ao conceito e contornos sobre os grupos de pressão.

\footnotetext{
${ }^{10} \mathrm{~A}$ exemplo das entidades representativas de classes; entidades representativas de grupos sociais tais como mulheres, negros, índios, jovens etc.

${ }^{11} \mathrm{~A}$ exemplo das entidades representativas de direitos coletivos e difusos tais como: o meio ambiente, a paz, à saúde, a dignidade da pessoa humana etc. Em complementação ao conceito de interesse público cita-se o artigo $3^{\circ}$, da Lei no 9.790 de 23 de março de 1999, que regulamenta as Organizações da Sociedade Civil de Interesse Público (Oscips).

12“'Os partidos socialistas e, a seguir, os partidos comunistas, desenvolveram a técnica das 'organizações anexas'. Tratava-se de grupos de pressão estreitamente ligados a um partido e submetidos, de fato, a suas diretivas". (DUVERGER, 1968, p. 456).
} 
Nesse aspecto, Luis Sanchez Agesta parte diferenciando grupo de interesse de grupo de pressão, em que no segundo caso, os objetivos fixam uma conduta orientada diante das instituições do poder público, pressionando sem substituí-las, de forma a provocar uma decisão, sem responsabilizar-se por ela. Assim, todo grupo de pressão é um grupo de interesse, residindo a diferença entre eles no campo de atuação, que no caso do grupo de pressão é junto ao poder público, pelo que, qualquer grupo de interesse pode vir a ser de pressão, motivado ao acaso ou constituído já com essa finalidade de vir a ser grupo de pressão. (SANCHEZ AGESTA, 1979). No que diz respeito às formas de ação específica dos grupos de pressão sobre o poder público, Agesta ainda reconhece a classificação ${ }^{13}$ de Jean Meynaud, que se daria pela persuasão, ${ }^{14}$ ameaça, ${ }^{15}$ suborno, ${ }^{16}$ sabotagem ${ }^{17}$ e ação direta ${ }^{18}$, sendo que Jean Meynaud trata tais formas como os possíveis perigos advindos dos grupos de pressão.

Com relação às formas, meios de ação dos grupos de pressão, Maurice Duverger divide em ação direta ao nível do poder e ação indireta ao nível do público, sendo que no primeiro caso a ação se dá diretamente sobre os detentores do poder, tais como, ministros, parlamentares, funcionários de alto escalão dentre outros, correspondendo essas ações a: ação de forma aberta, na qual os grupos exigem compromissos dos candidatos em época de eleição; ação oculta ou discreta efetivada pelo financiamento de candidaturas, ajuda material aos partidos, contatos pessoais com parlamentares, ministros, diligências no âmbito da administração pública; corrupção como sendo o pagamento em dinheiro, concessão de benesses, presentes, de forma crescente, até se chegar à corrupção coletiva que seria o financiamento dos partidos e das eleições; informação como forma dos grupos alimentarem o poder de informações que estes necessitam e não as possuem ou não as têm de forma técnica. Já a ação indireta, ao nível do

\footnotetext{
${ }^{13}$ Luis Sanchez Agesta resume as formas de pressão descritas por Jean Meynaud como sendo de persuasão, corrupção e intimidação. (SANCHEZ AGESTA, 1979, p. 231).

14،'L'un des moyens d'action qui s'offrent le plus naturellement aux groups est de chercher à persuader l'autorité compétente que leurs revendications sont justes: il s'agit, en somme, de constituer un dossier et de le plainer. C'est la méthode favorite de ceux qui aspirent à la 'respectabilité': convaincre par l'exposé d'arguments rationnels, fournir ce que les spécialistes anglo-saxons appellent the best advice”. (MEYNAUD, 1962, p. 54).

${ }^{15}$ “Ce procédé intervient lorsque les autorités se révèlent insuffisamment 'réceptives'aux yeux de leurs interlocuteurs. Les groupes vont plus ou moins loin dans cette voie et donnent une publicité plus ou moins grande aux actions entreprises ou envisagées; certains n’hésitent pas à déclarer ouvertement leurs desseins”. (MEYNAUD, 1962, p. 55).

16“'C'est um sujet sur lequel on dispose de plus de certitudes morales que de preuves écrites. En premier lieu, les ressources financières ouvrent aux groups la possibilité de renforcer et de perfectionner leurs moyens d'action courants (information et propaganda)”. (MEYNAUD, 1962, p. 56/57).

17“'Sabotage de l'action gouvernementale - Ses formes sont multiples, mais on en mentionnera seulement quelquesunes”. (MEYNAUD, 1962, p. 58).

18“'Il s'agit de ce que l’on appelle parfois l'épreuve de force (MEYNAUD, 1962, p.61).
} 
público, justifica-se em razão do poder levar em consideração a opinião pública. (DUVERGER, 1968, 459/463).

Assim, agindo-se sobre a coletividade das pessoas, pode-se indiretamente agir sobre o poder, correspondendo tais ações a: propaganda, que consiste na distribuição de informação orientada; métodos de violência que objetivam impressionar a opinião pública e levar o governo a ceder, por meio da desordem (a exemplo das greves gerais) e da agitação da ordem pública (como exemplo os bloqueios de ruas e estradas). (DUVERGER, 1968).

Com relação às associações e organizações que participam das formas de pressão, Maurice Duverger as divide em grupos de pressão e pseudogrupo de pressão, ${ }^{19}$ contendo o primeiro os grupos exclusivos, ${ }^{20}$ grupos parciais, ${ }^{21}$ grupos públicos ${ }^{22}$ e grupos privados, ${ }^{23} \mathrm{o}$ segundo os escritórios técnicos de pressão ${ }^{24}$ (caixas eleitorais, lobbies, escritórios de propaganda) e os jornais e órgãos de informação ${ }^{25}$ (de caráter comercial ou de pressão). Já Claudio Lembo faz uma catalogação diferente, identificando os grupos de pressão como grupos anômicos, ${ }^{26}$ não associativos ${ }^{27}$ e associativos.

Quanto à estrutura dos grupos de pressão, Maurice Duverger faz um comparativo com os partidos políticos, indicando que eles são grupos de massa ou de quadros. O grupo de massa busca agrupar o maior número de pessoas possíveis. É dele que tira sua força; sua organização é forte e hierarquizada. Já o grupo de quadros busca qualidade e não quantidade com relação às

19“Denominam-se assim as organizações que exercem uma pressão política, sem constituir grupos propriamente ditos”. (DUVERGER, 1968, p. 448).

20“Um grupo de pressão é exclusivo quando se ocupa unicamente com a ação no domínio político, como fazer pressão sobre os Poderes Públicos”. (DUVERGER, 1968, p. 443).

21“(...) um grupo é 'parcial’ quando a pressão política é apenas parte de sua atividade, quando ele tem outras razões de ser e outros meios de ação.” (DUVERGER, 1968, p. 444).

22،(...) as administrações agem por vezes segundo métodos mais ou menos análogos aos dos grupos de pressão. (...) Os diferentes serviços são em geral opostos entre si por rivalidades de influência mais ou menos agudas”. DUVERGER, 1968, p. 445).

${ }^{23}$ Maurice Duverger traz como referência de grupo privado a noção de grupo de pressão inicialmente elaborada nos Estados Unidos, que correspondiam a "ação de organizações e associações privadas sobre o poder". (DUVERGER, 1968, p. 445).

24،Trata-se de organizações puramente técnicas, de certo modo, às quais não corresponde qualquer comunidade, a não ser a que é constituída pelos próprios técnicos da organização”. (DUVERGER, 1968, p. 448).

${ }^{25}$ São organizações técnicas que podem ter caráter comercial ou de pressão, no primeiro caso são simples empresas que operam em ambiente capitalista e tem o lucro como objetivo, não são políticas ou educativas, no segundo caso buscam exercer pressão sobre o governo, poderes públicos ou opinião, dividindo-se em três faces: representam os meios de expressão de determinado grupo e normalmente são destinados ao público interno do grupo; composto pelos meios de informação e jornais financiados por grupos financeiramente poderosos que buscam influenciar a opinião pública e o governo; formado por instituições independentes que buscam exercer o 'magistério moral' sobre o poder e o público em geral. (DUVERGER, 1968, p. 450/452).

26“"Defendem interesses relativamente novos e não dispõem de critérios firmados para se orientarem”. (LEMBO, 1991, p. 50).

27“Baseiam-se em interesses relativos a segmentos sociais, religiosos, ou até mesmo de parentesco”. (LEMBO, 1991, p. 50). 
pessoas que o compõem. Isso se dá, por vezes, em razão do objetivo que pretende alcançar ou em razão da natureza das pessoas às quais o grupo se dirige. (DUVERGER, 1968, p. 453/455).

Com relação ao assunto, Andres Serra Rojas afirma que, nos países capitalistas, os grupos de pressão exercem influência sobre a política a ser implementada e sobre as decisões básicas do poder público. Já nos países comunistas, onde os grupos têm a mesma ideologia, esses exercem pouca influência sobre o poder, em razão do regime fortemente centralizado que os domina, mantendo-os submetidos às exigências do partido comunista. O autor pontua que os grupos de pressão não podem agir de forma arbitrária ou livre. Devem preparar seus associados com vista a unificar a ação, táticas e meios de que dispõem, com o objetivo de apresentar-se ante o Estado com força suficiente para dar sustentação a suas atitudes, de outro lado o Estado precisa dos grupos de pressão para apoiar suas ações políticas. ${ }^{28}$ (SERRA ROJAS, 1971, p. 713/715).

Prosseguindo no pensamento de Rojas, partidário do pensamento de Luis Sanchez Agesta quanto à divisão dos grupos em de interesses e de pressão, o primeiro compreende todas as atividades da vida social que demandam organização para alcançar algum propósito, objetivando realizar ideias ou fins particulares, ao passo que o segundo aparece quando os grupos de interesses se propõem a propósitos políticos. Observando que os grupos de pressão têm atividade política e não fins políticos, querem influenciar no governo e não exercê-lo, a atuação essencial do grupo de pressão é sobre a opinião pública e a ação governamental, mais especificamente sobre a ação legislativa e, por vezes, nas eleições.

O autor chama a atenção para o fato de que nos países onde os partidos são fracos, a forma da sociedade se comunicar com o Estado é através dos grupos de pressão. Segundo Rojas, existem duas correntes de opinião com relação aos grupos de pressão: uma os vê como instituições amorfas, imprecisas, de ação eventual e perigosa; outra entende que seu desenvolvimento está em escala ascendente e auxilia no debate dos interesses diversos da sociedade. (SERRA ROJAS, 1971, p. 716/731).

Um dos primeiros exemplos que se tem de forma legalmente reconhecida de grupo de pressão é o lobby ${ }^{29}$. Muito embora o Brasil não conte com uma legislação própria com relação ao assunto, constata-se a existência de suporte constitucional quanto à atuação dos grupos de

\footnotetext{
28“"El principal apoyo de un gobierno reside en la identificación de pueblo y poder. En la medida que las decisiones gubernamentales cuentan con la compresión y simpatía de la población, éstas encuentran el mejor camino para su realización. Actuar en contra de la opinión pública es caminar hacia la dictadura o al mal gobierno”. (SERRA ROJAS, 1971, p. 726).

${ }^{29}$ Regulamentado nos Estados Unidos por meio da Lei "Federal Regulation of Lobbying Act" datada de 02 de agosto de 1946 e lei mais recente, datada de 1995, a "Lobbying Disclosure Act”.
} 
pressão ante a garantia da livre manifestação do pensamento, plena liberdade de associação e o direito de petição.

Nesse ponto, para melhor aclarar o entendimento do que seja grupo de pressão, cita-se a observação de Alexandre Sanson que chama a atenção para o fato de que "por pressão, não se deve depreender o interesse do grupo, mas a significação íntima dos métodos utilizados na ação política condicionadora, residindo, consequentemente, na maneira de proceder e não no objeto associativo”. (SANSON, 2013, p. 114). O que leva a concluir que um grupo é caracterizado como de pressão, muito mais em razão da forma como atua do que por conta do objetivo perseguido em si, resultando assim que os grupos, por serem de pressão, não necessariamente perseguem objetivos egoísticos ou particulares, não devendo ser a priori mal entendidos, sofrer críticas, tendo em vista que colaboram com a diversidade social.

Após a análise e descrição dos grupos de pressão, faz-se útil a definição do termo, segundo a ótica de alguns autores. Para Luis Sanchez Agesta, grupo de pressão, em sentido geral é “toda associação (...) que defende os interesses comuns ou seus membros mediante uma ação sobre os órgãos legislativos, administrativos ou sobre os partidos políticos ou sobre o eleitorado através da opinião pública”. (SANCHEZ AGESTA, 1979, p. 227).

No sentido de dar a noção de grupo de pressão, Maurice Duverger parte da diferenciação entre partido político e grupo de pressão, na qual o primeiro pretende conquistar e exercer o poder e o segundo agir, influir sobre o poder mantendo-se fora dele, pontuando que "a maior parte dos grupos de pressão são organizações não políticas, cuja atividade essencial não é a pressão sobre o poder”, sendo que qualquer associação “pode vir a agir como grupo de pressão em certos setores e em certas circunstâncias”. (DUVERGER, 1968, p. 442).

Para conceituar grupos de pressão, Andres Serra Rojas afirma que “são as organizações ou coalisões de interesse econômico, que sem ser políticas ou valendo-se de uma política como um meio, têm por missão defender os interesses, objetivos ou propósitos do grupo, ao mesmo tempo que influem nas decisões governamentais ou na política geral de um país, diretamente, ou através de personalidades políticas influentes ou fazendo um chamado à opinião pública por meios diretos ou indiretos”. (SERRA ROJAS, 1971, p. 713).

Na opinião de Rafael Rubio Núñez, o essencial do conceito de grupo de pressão seria: uma união de pessoas organizadas; uma técnica de atividades de gestão; um sujeito ativo, profissional ou não, e um sujeito passivo com poder legislativo; um objeto, medidas legislativas ou regulamentares; um fim, um interesse dos sujeitos que formam a organização, propondo como definição “toda união autônoma e organizada de indivíduos, que leve a cabo ações para 
influir no poder legislativo ou executivo em defesa de seus interesses comuns”. (RUBIO NÚÑEZ, 2003, p. 177).

Agora, analisando o papel do terceiro setor para a sociedade civil e fazendo um cotejo com as palavras de Maurice Duverger, quando afirma que “os grupos de pressão, não participam diretamente da conquista do poder e de seu exercício: agem sobre o poder, mas permanecendo fora dele; fazem 'pressão' sobre ele (...) procuram influenciar os homens do poder” (DUVERGER, 1968, p. 442), explicitando todavia que, “a maior parte dos grupos de pressão são organizações não políticas, cuja atividade essencial não é a pressão sobre o poder” (DUVERGER, 1968, p. 442), mas que pode vir a agir como grupo de pressão a depender das circunstâncias, verifica-se uma correspondência entre grupos de pressão e terceiro setor.

O terceiro setor é uma forma de organizar e estruturar o grupo de pressão, com o intuito de que esse alcance seus objetivos, qual seja, influenciar no locus do poder, alterando ou barrando uma lei ou uma decisão, pela pressão.

A falta de legislação com relação ao lobby no Brasil, que segundo Duverger é um “pseudogrupo” de pressão, ${ }^{30}$ pode ser compensada pelo terceiro setor, que como tal, tem assento em várias comissões (secretarias, órgãos públicos, controladorias etc), participando e influindo dentro do próprio poder, constituindo assim uma forma de pressão que não de fora para dentro, chegando a propor e, até mesmo, executando políticas públicas de seu interesse por meio das parcerias e convênios com o poder público.

Os grupos de pressão operados pelo terceiro setor são uma forma de representação das minorias, especialmente daquelas que não alcançaram eleger um representante no parlamento. A democracia não pode ser, assim como no pensamento de Tocqueville, a opressão, subjugação da maioria sobre as minorias e não deve aniquilar ou ignorar as minorias, mas sim buscar compor os lados do jogo político.

Pontua-se, ainda, que com relação ao cenário político brasileiro da atualidade, a democracia é operada por uma multiplicidade de partidos, ideologicamente frágeis e pasteurizados. Nesse ambiente, os grupos de pressão representam grande aliado da sociedade na busca de seus interesses, uma vez que a representação política não está cumprindo seu papel.

Deve ressaltar que o ser humano é multifacetado, tendo em vista que o indivíduo participa de vários grupos ao mesmo tempo (família, religião, trabalho, sociedade etc), fazendo

\footnotetext{
30“Denominam-se assim as organizações que exercem uma pressão política, sem constituir grupos propriamente ditos. Reúnem um certo número de indivíduos e formam assim uma comunidade. Mas estes indivíduos são técnicos, que nem sempre exercem a pressão para si próprios, e sim por conta de outros grupos”. (DUVERGER, 1968, p. 448).
} 
com que os indivíduos, na sociedade plural, desenvolvam-se num processo de interação recíproca e de interdependência.

Ninguém e nada é uma única coisa, tudo é construído pela união de várias partes. O terceiro setor vem a contribuir com essa construção, na medida em que age como grupo de pressão, defendendo e lutando pelas várias partes, que ao final encontrarão o todo, o bem comum.

O terceiro setor, enquanto grupo de pressão, não deixa de ser uma forma de representação, não outorgada pelo voto ou dentro do parlamento, mas legitimada de forma direta por aqueles que compõem o grupo, um “parlamento” de fato, no meio social, denominado de terceira casa do legislativo por Paulo Banavides. ${ }^{31}$

Pontua-se, ainda, que o terceiro setor também busca o bem público, o bem-comum, o atendimento ao social, especialmente com relação à boa parte do terceiro setor, que é composta pelas entidades de fins públicos (em diferenciação às entidades com interesses voltados a um grupo específico, tal como as organizações representativas de classes). Essas entidades estão em consonância com a vontade da maioria e do bem social e não deveriam sofrer as críticas e consequências negativas quanto a sua atuação, uma vez que constituem uma forma legitima de representação, mesmo que não oriunda do meio parlamentar, podendo-se dizer que são uma face da democracia participativa. ${ }^{32}$

Sob o aspecto da participação, levando-se em conta que as entidades do terceiro setor têm um viés de grupo de pressão, Rafael Rubio Núñez discorre que os grupos de pressão situamse como atores da democracia participativa e como elementos complementares, democratizantes, da democracia representativa. Convertem-se em sujeitos que ampliam a democracia participativa proporcionando a participação real, efetiva. É ao redor dos grupos que se construiria o espaço público necessário para uma democracia forte e consolidada. Para o autor, a participação dos grupos na vida política atende a uma dupla perspectiva: por um lado o maior e melhor conhecimento da opinião dos interessados nos assuntos submetidos à discussão parlamentar e, por outro, o fornecimento de uma maior racionalidade que permita criar o foro público para a discussão de forma democrática, constituindo a nova configuração da representação política. (RUBIO NÚÑEZ, 2003, p. 202/204).

\footnotetext{
31“Nos Estados Unidos, os lobbies reconhecidos por lei e exercendo atividade regular se converteram numa espécie de "terceira casa” do poder legislativo". (BONAVIDES, 2012, p. 477).

32“A informação oriunda dos grupos altamente competentes pode construir valioso subsídio à elaboração legislativa ou à tomada de decisão administrativa, na qual em verdade não seriam raras as vezes em que ocorreria coincidência ou identificação do interesse geral com os interesses abertamente propugnados pelo grupo". (BONAVIDES, 2012, p. 474).
} 
Assim como no parlamento, em uma democracia deve-se travar o embate das ideias, discutir, deliberar, sendo que as entidades que compõem o terceiro setor também o fazem, levando ao conhecimento da sociedade, tal como os grupos de pressão, várias facetas de uma temática. $^{33}$

Nesse sentido, o terceiro setor como fonte de informação e recursos, o é não somente para a sociedade, mas também para o Estado. Facilita informação e recursos que resultam úteis ao processo político, o quanto fornecido é necessário tanto para o poder legislativo quanto para o executivo. Essa informação e esses recursos ajudam a manter os membros do governo em contato com os cidadãos do país. Uma democracia interativa precisa da participação cidadã, e as entidades do terceiro setor são essenciais para facilitar a chegada da opinião das pessoas ao governo. $^{34}$

A representação, que deveria ser operada pelos partidos, mas que não tem sido, provavelmente em razão da degeneração e da pasteurização de suas ideologias, pode ser preenchida, de forma subsidiária, pelo terceiro setor enquanto grupo de pressão, que vem a preencher a lacuna deixada pelos partidos, no sentido de influenciar no locus governamental. ${ }^{35}$

O terceiro setor atua não só como “uma casa legislativa” externa ou “governo auxiliar”, mas também faz as vezes de oposição em certa medida, de forma a manter o pêndulo da democracia em movimento. Além disso, auxilia no equilíbrio das forças, que hoje, num Brasil sem partido vocacionado a ser oposição, torna-se relevante e útil à manutenção da democracia.

\section{CONCLUSÃO}

\footnotetext{
33“'São trazidas à luz, por todos os ângulos possíveis sempre que os grupos se acham em luta e a oposição de um é combinada por outro, informações que deixam a opinião pública bem inteirada acerca de questões cujas particularidades lhe eram desconhecidas”. (BONAVIDES, 2012, p. 475).

${ }^{34}$ Record do Senado dos Estados Unidos. Mr. Glenn, Senador por Ohio, Lobbying Disclosure Act of 1993. Conference Report. S14286. (RUBIO NÚÑEZ, 2003, p. 203).

35“'Desde que a ação dos grupos também recai sobre o executivo, tomaram ali toda a aparência de uma modalidade de 'governo auxiliar'”. (BONAVIDES, 2012, p. 477).
} 
A democracia é um regime político almejado pela sociedade, tendo em vista a possibilidade da grande massa da população participar do estreito círculo em que se desenvolve, não só a luta pelo poder, como o seu próprio exercício.

Em tempos atuais a democracia é representativa, o povo, por meio do voto, entrega nas mãos dos eleitos o poder, constituindo este a forma de participação no locus governamental.

Na sistemática da representação, o povo cede o exercício do poder calcado na boa-fé de que será usado para o atendimento dos clamores sociais e com vistas ao bem comum, contudo não é o resultado que se tem assistido no cenário brasileiro.

Diante da ineficiência dos eleitos e da degeneração da classe política, os cidadãos tem buscado formas de uma participação mais ativa no Estado, conduzindo-se para uma democracia participativa.

Na busca de maior influência e participação nas decisões governamentais, a sociedade identificou no terceiro setor uma forma de atuar junto ao poder, possibilitando uma interferência direta neste.

Neste sentido, as entidades atuam como verdadeiros grupos de pressão, são uma forma de organizar e estruturar os cidadãos, com o intuito de que seus objetivos sejam alcançados, tanto no sentido de alterar ou barrar uma lei, quanto no caminho de modificar uma decisão política.

Esse alargamento da participação democrática, por meio do terceiro setor enquanto grupo de pressão, é assistido no cenário brasileiro, tendo como principais exemplos os movimentos de rua, o emprego de pressão sobre julgamentos célebres e organização e propositura legislativas por intermédio de iniciativa popular.

A eficiência deste modelo de atuação fica evidente ao olharmos o passado político recente do Brasil, no qual os movimentos sociais, organizados pelo terceiro setor, utilizaram as manifestações de rua como uma das estratégias para alcançar seus objetivos. Elas propiciaram uma ampliação da capacidade de intervenção da sociedade sobre a política, podendo identificarse três ciclos de mobilização: “Diretas Já” (1983/1984), “Movimentos pela Ética na Política” ou "Fora Collor" (1992) e os protestos de junho de 2013 que culminaram no impeachment da Presidente Dilma Rousseff.

Os movimentos de rua, de forma organizada, atuando como verdadeiros grupos de pressão, foram capazes de trazer a abertura democrática e a deposição de dois Presidentes da República, sob os quais pairavam dúvidas sobre a sua moralidade pública. 
No que diz respeito à intervenção legislativa a sociedade, castigada pela violência e sua respectiva impunidade, bem como pela falta de ética na política, sem qualquer providência por parte dos políticos, apresentou projeto de lei, posteriormente apadrinhado pelo Legislativo, que deram origem à Lei $\mathrm{n}^{0}$ 8.930/1994 (ampliação do rol dos crimes hediondos) e à Lei Complementar $n^{\circ}$ 135/2010, mais conhecida como "Lei da Ficha Limpa”, que dispõe sobre casos de inelegibilidade, incluindo hipóteses que visam proteger a probidade administrativa e a moralidade no exercício do mandato.

A atuação do terceiro setor, enquanto grupo de pressão, estendeu-se para além do Legislativo e Executivo, hoje opera inclusive sobre o Poder Judiciário. Tal fato pode ser identificado claramente em dois momentos, um na ocasião do julgamento do mensalão e, outro mais recente, são os diversos abaixo assinados entregues ao Supremo Tribunal Federal, às vésperas do julgamento do habeas corpus preventivo impetrado pela defesa do ex-Presidente Luis Inácio Lula da Silva (HC nº 152752).

No caso do mensalão, para a sociedade, o desfecho do julgamento representava a afirmação de que todos são iguais perante a lei e, neste sentido, a mídia e o terceiro setor mantiveram-se vigilantes e fizeram pressão. Como exemplo, cita-se a iniciativa de entidades do terceiro setor preocupadas com a demora no julgamento do caso, que poderia ter como consequência a prescrição dos crimes cometidos por vários réus da Ação Penal nº 470. Destacase o movimento “Nas Ruas” e “Revoltados Online”, que realizaram um mutirão em pelo menos 15 cidades do Brasil para colher assinaturas pedindo ao Supremo Tribunal Federal agilidade no julgamento do processo do “mensalão”. A ONG Transparência Brasil, em um ato simbólico, foi até Brasília para entregar ao Ministro Ricardo Lewandowski uma ampulheta simbolizando o tempo. ${ }^{36}$ Outro exemplo foi a iniciativa da ONG Brasil Verdade, sediada em Campo Grande, que entrou com pedido no Supremo Tribunal Federal com o intuito de que o Ministro José Antônio Dias Toffoli fosse impedido de participar do julgamento do "mensalão", sob o argumento de que ele à época do escândalo, em 2005, era subchefe para assuntos jurídicos da Casa Civil, comandada por José Dirceu, réu no processo e também porque a namorada do Ministro teria sido advogada de outros três denunciados no esquema do "mensalão". ${ }^{37}$ Muito embora a

\footnotetext{
${ }^{36}$ Fonte: MUCO. Ongs cobram urgência no julgamento do mensalão. MUCO, [s.d.]. Disponível em: $<$ http://www.muco.com.br/index.php?option=com_content\&view=article\&id=2709:ongs-cobram-urgencia-nojulgamento-do-mensalao\&catid=36:em-exibicao\&Itemid=55>. Acesso em: 7 jan. 2016.

${ }^{37}$ SANTOS, Aline. Ong de MS quer impedir que ministro participe do julgamento do mensalão. Campo Grande News, Julho de 2012. Disponível em: http://www.campograndenews.com.br/politica/ong-de-ms-quer-impedirque-ministro-participe-do-julgamento-do-mensalao >. Acesso em: 7 jan. 2016.
} 
iniciativa de arguição de suspeição não tenha logrado êxito, deixou muito clara, para a Corte do Supremo, a vigilância da sociedade civil organizada sobre as atitudes dos Ministros.

Os fatos apontados deixam claro que o terceiro setor, enquanto grupo de pressão, é uma forma eficaz e direta de intervenção no locus governamental, vindo a influir nas três esferas do poder, de tal forma que a vontade e o anseio da sociedade sejam atendidos, funcionando como uma verdadeira ferramenta capaz de reorientar os resultados, no sentido de forçar o acatamento da vontade popular, constituindo-se em verdadeira forma de exercício da democracia participativa.

\section{Bibliografia}

ALVES, Sergio Luís Mendonça. O papel constitucional da sociedade civil na definição de políticas públicas. In: SZAZI, Eduardo (Org.). Terceiro setor. São Paulo: Petrópolis, 2005.

BONAVIDES, Paulo. Ciência política. São Paulo: Malheiros, 2012.

BVERFGE 69, 315 (BROKDORF), datada de 14/05/1985.

CAGGIANO, Monica Herman Salem. Oposição na política: proposta para uma rearquitetura da democracia. São Paulo: Angelotti, 1995.

- Finanças partidárias. Dissertação (Mestrado) - Universidade de São Paulo, Faculdade de Direito, 1980.

COELHO, Simone de Castro Tavares. Terceiro setor: um estudo comparado entre Brasil e Estados Unidos. São Paulo: Editora Senac São Paulo, 2005.

DAGNINO, Evelina. Democracia: teoria e prática. Rio de Janeiro: Relume Dumará; Curitiba: Fundação Araucária, 2002.

DURIGUETTO, Maria Lúcia. Sociedade civil e democracia: um debate necessário. São Paulo: Cortez, 2007.

DUVERGER, Maurice. Sociologia política. Rio de Janeiro: Companhia Editora Forense, 1968. FERREIRA FILHO, Manoel Gonçalves. A Reconstrução da democracia: ensaio sobre a institucionalização da democracia no mundo contemporâneo e em especial no Brasil. São Paulo: Saraiva, 1979.

GOMES, Wilson; MAIA, Rousiley C. M. Comunicação e democracia: problemas \& perspectivas. São Paulo: Paulus, 2008. 
HABERMAS, Jürgen. Direito e democracia: entre facticidade e validade. Rio de Janeiro: Tempo Brasileiro, v.II, 2011.

LEMBO, Claudio. Participação política e assistência simples no direito eleitoral. Rio de Janeiro: Forense Universitária, 1991.

LIJPHART, Arend. Modelos de democracia: desempenho e padrões de governo em 36 países. Rio de Janeiro: Civilização Brasileira, 2003.

LOEWENSTEIN, Karl. Teoría de la constitución. Barcelona: Editorial Ariel, 1976.

MEDAUAR, Odete. Direito administrativo moderno: de acordo com a EC 19-98. $3^{\mathrm{a}}$ ed. rev. atual. São Paulo: Revista dos Tribunais, 1999.

MEYNAUD, Jean. Les groupes de pression. Paris: Universitaires de France, 1962.

RUBIO NÚÑEZ, Rafael. Los grupos de presión. Madrid: Centro de Estudios Políticos y Constitucionales, 2003.

SANCHEZ AGESTA, Luis. Principios de teoría política. Madrid: Editora Nacional, 1979.

SANSON, Alexandre. Dos grupos de pressão na democracia representativa: os limites jurídicos. Tese (Doutorado) - Universidade de São Paulo, Faculdade de Direito da Universidade de São Paulo, 2013.

SARTORI, Giovanni. Elementos de teoría política. Madrid: Alianza Editorial, 2012. . Homo videns: televisão e pós-pensamento. Bauru, SP: EDUSC, 2001.

SCHWARTZENBERG. Roger-Gérard. Sociologia política. Elementos de ciência política. Tradução Domingos Mascarenhas. Rio de Janeiro: DIFEL, 1979.

SERRA ROJAS, Andres. Ciencia política. Estructura y proyección de las instituciones políticas contemporáneas. México: Instituto Mexicano de Cultura, 1971.

TEIXEIRA. Josenir. O terceiro setor em perspectiva: da estrutura a função social. Belo Horizonte: Fórum, 2011.

TOCQUEVILLE, Alexis. A democracia na América. Belo Horizonte: Itatiaia; São Paulo: Ed. da Universidade de São Paulo, 1987. 